\title{
TNF Superfamily Member 12 Excretion Rate
}

National Cancer Institute

\section{Source}

National Cancer Institute. INF Superfamily Member 12 Excretion Rate. NCI Thesaurus.

Code C156525.

The determination of the amount of TNF superfamily member 12 being excreted in a biological specimen over a defined period of time. 